Article

\title{
Dual Control: Investigating the Role of Drone (UAV) Operators in TV and Online Journalism
}

\author{
Catherine Adams \\ Journalism and Media, Nottingham Trent University, Nottingham, NG1 4FQ, UK; E-Mail: catherine.adams@ntu.ac.uk
}

Submitted: 3 March 2020 | Accepted: 28 April 2020 | Published: 27 July 2020

\begin{abstract}
At a time when TV and online journalism embraces more moving images filmed from drones than ever before, this article seeks to explore the thoughts and actions of those who produce them. It builds on earlier research into how aerial images impact on the viewer through the lens of 'quality journalism' (Adams, 2018). It investigates how drone operators are involved in the journalistic process, what meanings and effects they seek and who controls their work in a market-driven environment. Qualitative analysis was carried out of seventeen in-depth interviews with drone operators, journalists and editors working in UK and around the world. Data revealed a high degree of creative freedom among the operators, a passion for using drones and some desire to immerse and impress the viewer. It showed that aerial images have become paramount in video journalism amid market pressures to find ever more sophisticated and 'cinematic' shots. Interviewees felt drones had been "good for journalism," by providing raw data, exciting new perspectives, context and story-telling techniques and "space to think." The article explores the significant yet often unplanned contribution to the journalistic process of the drone operator and recommends more is done to increase understanding between journalist and pilot, such as providing training courses designed to teach quality drone journalism, as the media approaches 'peak drone.'
\end{abstract}

\section{Keywords}

drone; journalism; operator; pilot; TV; unmanned aerial vehicles

\section{Issue}

This article is part of the issue "Journalism from Above: Drones, the Media, and the Transformation of Journalistic Practice" edited by Jonas Harvard (Mid Sweden University, Sweden), Mats Hyvönen (Uppsala University, Sweden) and Ingela Wadbring (Mid Sweden University, Sweden).

(C) 2020 by the author; licensee Cogitatio (Lisbon, Portugal). This article is licensed under a Creative Commons Attribution 4.0 International License (CC BY).

\section{Introduction}

As online and broadcast journalism embraces more moving images filmed from unmanned aerial vehicles (UAVs) than ever before, it is timely to deepen the research in this field by investigating the thoughts and actions of those who produce the shots. Although much has been written about the impact of the digital revolution on journalists' jobs, such as multi-skilling and convergence, a glimpse into the camera operator's point of view is rare.

The term 'dual control' is a reference to a system where two consoles are plugged into the same aircraft: one for an operator to fly and direct the drone itself, and the other for a person to work the camera. The operator and camera person can stand close together, discuss and collaborate in order to decide what and how to film. Most UAVs now are operated by one person with 'single control' but the phrase 'dual control' is useful in the context of this study, which seeks to explore the roles of operator and journalist and how they work together and interact. For the purposes of this article, the term 'operator' will be used interchangeably with 'pilot' and the term 'journalist' will be used to describe anyone involved in making journalistic decisions, such as reporter, editor or producer.

The role of drone operator is relatively new and previous research into the cross-over with the role of journalist is hard to find. Unlike jobs in the news industry which merged to produce new roles such as the 'video journalist,' (adding filming skills to reporting and editing ones), UAV pilots have so far tended to work as special- 
ist technicians; 'drone journalists' exist but are uncommon. However, the newsgathering carried out by drone operators, as by any camera person or photographer, is bound to involve a degree of editorial decision-making which must affect the journalistic output. It is this involvement by drone operators in journalism which is of concern here, not least because research has shown that early adopters of new technology are more likely to want to please their TV consumers than their journalist colleagues (Wallace, 2009).

We know from previous research that drones have not turned out to be the widely predicted 'gamechangers' of the industry, but that they have brought new 'players' and 'narratives' to the 'game' of journalism. A multiple case study of audio-visual news and feature items from several different countries (Adams, 2018) identified thirteen hypothetical perspectives or 'narratives' in aerial filming which potentially affect journalism. These included a diagnostic view, a sense of global connection, drama through movement, a feeling of (unrealistic) power, suggestion of surveillance, beauty or art, unnecessary gloss and occasionally the immersion of the viewer. Some shots were found to enhance while others detracted from the quality of the journalism. This research puts these 'narratives' to the test by presenting them to drone users themselves for comment and asks, among other things, whether their actions are deliberate or unconscious.

The article is based on in-depth interviews with operators based in the UK and the journalists they work with in order to try to answer four key questions: what the current role and status of the drone pilot is, how they are involved in the journalistic process, what meanings and effects they seek through drone-filming and whether any of their work is threatening the quality journalism needed for a functioning democracy.

\section{Journalism and Quality Control}

When judging the effect of drones in this medium, it is important to revisit the underlying aims of journalism itself. In its most basic sense, journalism aims to report or tell its audience what is happening, often in the form of a story. 'Democratic' or 'quality' journalism is defined in professional codes of conduct and industryaccredited guidelines and training courses across the world. Among its recognisable traits, perhaps none is as important as the idea of the journalist as 'truth-seeker.' The concept of the press as the Fourth Estate, speaking truth to power and 'monitoring' the establishment mostly prevails, even while journalism is constantly undermined (McQuail, 2013, p. 112).

Authors agree that quality journalism should also reveal something which is not only new but also of substance (de Beer \& Merrill, 2008, p. 17; Ray, 2003, p. 23), presented in 'original' form (Shapiro, 2014, p. 561), factbased, neutral, accurate and proportional (Deuze, 2005, p. 447) and serving a public interest (Curran \& Gurevitch,
2005 , p. 144) or even a 'public enlightenment' function (SPJ, 2014). Professional bodies state that journalism recognises the right of the public to information and truth (IFJ, 2020; NUJ, 2018). It is incumbent on journalism to communicate well and explain (Ray, 2003, p. 23), provide insight and/or analysis and engage viewers through means such as drama, visual attractiveness and entertainment (Golding \& Elliott, 1979, pp. 115-118). There is also an expectation in our modern networked society that it should present audiences with context, a wide range of voices (Overholser, 2009) and link the local to the global (Zuckerman, 2013, p. 7). It should ask difficult questions and challenge the status quo (Greenwald, 2014 , p. 230). Journalism should convey not only facts, but discourse and cultural information (Auslander, 1999, p. 2). In order to be trusted, it needs to display "ability, benevolence and integrity" (Blöbaum, 2016, p. 8) and above all to balance engagement and objectivity. As one of the editors interviewed put it: "There's a massive element of trust and once we overstep that mark we're in trouble. Viewers have to believe what they see" (M. Dolan, personal communication, January 20, 2020).

It is important to highlight that journalism is struggling to retain this trust and to control its future in the face of market forces and economic pressures (Deuze, 2008, p. 5). The news industry is forced to attract larger revenues' which "may not be in the public interest" (Dominick, Wurtzel, \& Lometti, 1975, p. 213). The knockon effect is to reduce the range of angles, opinions and sources journalism offers (Davies, 2008, p. 203), to cut fees, salaries and resources, to over-simplify complex issues and to rely more heavily on public relations and business interests (Greenwald, 2014, p. 233). In short, increased commercialisation leads to a lowering of news standards. Cheaper, digital technology presents challenges such as online interactivity which undermines journalism via clickbait as "audience feedback seems to take centre stage" (Phillips, 2014, p. 6). It has also brought about shifts in journalism practice, including multi-skilling, multi-platform production and the blurring of news and entertainment (Lee-Wright, Phillips, \& Witschge, 2011, p. xi) which can "imperil the public service function of the media" (p. 13). In this context, the introduction of drones to the journalism industry has brought both welcome and unwelcome changes.

\section{The Drone's Point of View}

Drones were expected to be 'game-changers' for media and society (Hamilton, 2015; Roug, 2014), a disruptive innovative technology (Belair-Gagnon, Owen, \& Holton, 2017) which would transform journalism and markets (Levine, 2014) and signal new value networks (Gynnild, 2014 , p. 360). Aerial filming was regarded as 'central to modern imagination' and viewers' appetite for it "everincreasing" (Dorrian \& Pousin, 2013, p. 9). Drones have even been attributed with the power to "change the way that we see" (Rothstein, 2015, p. 125). Drones, also 
known as UAVs, were "set to go mainstream" (Waterson, 2014) and to revolutionise news reporting (Waite, 2014). Scholars identified the 'emergent genre' of drone journalism (Gynnild, 2014, p. 334; Hamilton, 2015). At the same time, critics warned of 'drone fatigue' (Wyndham, 2017), 'drone fetishism' (Krisis, 2017) and a "short-lived novelty wow factor" (Rocha, 2016).

Gynnild and Uskali highlighted a lack of research into following up these predictions and expectations of drones in journalism (2018, p. 8). Scholarly investigation to verify them or look at their effect on media discourse has been slow to catch up (Belair-Gagnon et al., 2017, p. 11; Chamayou, 2014; Choi-Fitzpatrick, 2014, p. 31). Recent work has now produced a number of indications and insights into the use of aerial footage in TV news (Adams, 2018): namely that drones are used in news more often to provide context than content; that they are not revolutionising newsgathering but can undermine quality journalism by encouraging style over substance. Drone footage can potentially immerse viewers, with the danger that they lose their objective, critical perspective on the story and the absence of interviews can de-humanise a topic, as distant views replace a grittier reality.

Building on these findings, drone shots can be categorised into three types by looking at the degree of control which they seem to offer or suggest to the viewer. The 'informative' ones treat the viewers as passive 'learners,' informing them or helping them to understand the story. This type includes footage which underlines story content, adds meaning or insight and creates a sense of global context. This plays out one of the classic roles of quality, Reithian journalism. On other occasions, edited footage can take the viewer on a journey by framing a story (deliberately or otherwise) to produce an effect on their perception. This second type of 'journey' shot might, for example, turn a landscape into an aesthetic entertainment, for example displaying a rural scene as a patchwork quilt, imitating surveillance or military reconnaissance, presenting a diagnostic, quasi-scientific view, or creating armchair super-power shots which mimic video-gaming. In this case, it gives viewers a false sense of control, or "manufactured authority," to quote Marek Vanzura (2019), turning views into something else, or something "unreal." Thirdly there are shots which result in the viewer feeling out of control. These 'fairground' or 'floating' shots can immerse the viewer and take them on a wild, playful 'ride,' using unexpected dramatic movement. An audience might enjoy the feeling of escapism, novelty and liberation from the ground, or feel distracted from the story itself, depending on the context. These last two types may be more about entertaining the viewer than telling the story.

\section{Angle and Trajectory}

My approach was to focus mainly on the operators and investigate the part they play in determining and controlling the form, content and style of journalistic prod- ucts and in shaping narratives by finding, choosing and filming their footage. I sought to find out what was going through the minds (not only of the pilots, but also their journalistic counterparts) and to probe their deeper knowledge and understanding of drones to seek more general insights into contemporary and future practice and culture.

I used a variety of methods to identify and approach drone operators, starting with my own professional network of journalistic contacts, then searching online for drone operators and approaching the main local and regional broadcasters, BBC and ITV. I submitted a request for interviewees through the National Union of Journalists newsletter and the Association of Drone Operators. The sampling followed a snowballing pattern, often added to by personal contacts and word of mouth recommendations. This led to a broad spectrum of interviewees, some who worked internationally and others on region-wide level. The interviews were mostly with drone pilots who were purely technical camera operators (eleven), but I also interviewed five journalists (reporters, editors and producers), who worked closely with operators, and one who carried out both roles simultaneously, as a 'drone journalist,' in order to see how their perspectives differed or complemented each other. In two cases I was able to interview a pilot and journalist (editor) together to observe the dynamic between them. The other eleven pilots strongly resisted the suggestion that they were also journalists, although their work sometimes included editing the footage.

Qualitative analysis was carried out into seventeen semi-structured in-depth interviews of drone operators and journalists: fifteen men and two women; fifteen white and two of colour. They came from various professional backgrounds, mostly journalism, photography and camerawork, but also the police, insurance and building industries. They included early adopters and newcomers, working for a range of local, regional, national and international news, entertainment and current affairs programmes, both public service and commercial. The sample size recommended for this kind of research can be from five to fifty interviewees (Dworkin, 2012) depending on the quality of information gathered. In this case, the process reached saturation point by the seventeenth interview and no new, relevant data was forthcoming.

The interviews took on average an hour and were carried out either in person (eight) or on the phone (nine) and recorded and/or transcribed. Interviewees were presented with twenty-two questions divided into six sections and a list of the thirteen 'narratives.' They were asked how they 'got into' drones; why they enjoyed using them; why drone footage was used; what kind of shots they liked; what they saw, felt, or thought when filming, editing or producing; what the relationship was between operator and journalist; whether drones had changed journalism; whether the 'narratives' resonated with them and how they saw the future of drone journalism. The aim of the interviews was to seek exploratory 
data through their comments and descriptions, looking for patterns and themes, nuances and tensions and deep information or knowledge (Hesse-Biber \& Leavy, 2005) with regard to the four research questions.

A distinction should be made here between the types of journalism in question. This article discusses the use of journalism in both news and features (longer ones coming under the heading of 'programmes' in the television industry). News differs starkly from features in that items are conventionally shorter and more factual while a feature seeks new insight into a topic and can be crafted in a more creative or dramatic way to sustain audience engagement. It is to be expected therefore that drones are used in different ways for each.

\section{The 'Reveal'}

\subsection{The Role of the Drone Operator}

The role of the UAV pilot in journalism has not only been enhanced by the increased number of pilots employed in the news industry, but in the status of drones themselves. Interviewees working in the UK said they had experienced a great deal of freedom to film and found that they could do almost anything: "people are relaxed" about drones, one said. Although laws and restrictions vary greatly around the world, several felt that the general public were used to journalism drones and had warmed to them. Pilots revealed as a "trick of the trade" that editors would sometimes add the sound of a helicopter over the drone shots, because it sounded "more authentic" and powerful than the feebler whir of the UAV blades. It must be concluded that this marginally unethical practice also serves to enhance the status of the drone and remind the viewer of its presence.

The research indicated that the use of drones was widespread and would almost certainly continue to be, depending on the format. Interviewees from UK programmes (features, documentaries and drama) said they had "reached peak drone," as Choi-Fitzpatrick predicted (2014, p. 32), while in regional news there was "still room" for "much more." In national programmes the trend was for more "filmic, stylised" sequences whereas local and regional TV newsgathering "aren't bothered about quality, just the story." Regional BBC TV documentaries were "expected" to use drones heavily, partly because they had more time to plan, whereas interviewees working in daily news said they were currently only using them approximately twice a month.

Operators' comments revealed that they were in a strong, privileged position, because it was often impossible for colleagues on the ground to know what the shots would look like until the drone went up in the air, when they were the first to see the images: "You don't know what you're going to get," as one put it. This gave them exclusive access and perhaps enhanced their status visa-vis the journalist, or at least made the work more fun than other kinds of filming.
The operators' passion and love of drone filming came across very strongly in the interviews. They often associated words "love" and "like" with their aerial filming work. I had not expected to find such emotional attachment to what is essentially a routine technical job. One remarked on the intellectual challenge of "making you think in a completely different way"; another said they liked to film with drones "because it's cool." The drone was referred to both "toy" and "tool": one operator said he was "aware it's not a toy," associating it simultaneously with playfulness and work.

\subsection{The Operators' Involvement in the Journalistic Process}

The overriding view among the interview subjects was that drones were now a vital part of the job of journalism: shots were described by journalists as "very powerful" and "so valuable"; aerial footage was now "a staple" in TV news and current affairs, where "it's all about the pictures," with drones regarded as "essential tools" of the trade. If aerial shots were available, they would automatically be used as 'teasers' for the news item. The strength of images has long been a determining factor in prioritising news stories (Hunt, 1999, p. 94) and the importance of drone shots has already been suggested by their frequent appearance as headline or opening shots (Adams, 2018).

Although most of the operators were not journalistically trained, they nevertheless understood that 'the story' was paramount and that simulating videogaming was 'not appropriate' for news. There was widespread criticism of poor or pointless drone shots on TV, an admission that some stories would not have aired without the drone shots and several complaints about "overkill" and "overdroning" which could confuse or bore viewers. This showed that these drone users understood some of the requirements of quality journalism, even though they were not journalists, and wanted to work within its parameters.

The relationship between pilot and journalist was a key insight provided by the data, which suggested that this varied widely in terms of who had dominance over what was filmed and used in the final product. One operator said the "reporter reins me in," while another experienced "heavy handed or prescriptive" editing. Several pilots were given carte blanche to get the shots they liked and some "guided the reporter" rather than the other way around. Two referred to the practice of the journalist acting as "observer" for their pilot during filming (a legal requirement), making them their technical assistant in a temporary role reversal. In one joint interview the operator described an increase in his status and authority, due to new skills, accreditation and knowledge about permissions and regulations, which his editor was keen to underplay, insisting that he simply "contributes."

The data often revealed a lack of communication and a wide knowledge gap between operator and journal- 
ist: Pilots reported journalists "not knowing" what shots they wanted and criticised inexperienced operators who "don't think about the pictures." None of the subjects had had any training on drone filming for journalism and there was a lack of universal code to describe shots, so they had often developed their own working language and terminology with colleagues. In one case the operator admitted he did not use any specialist language at all and his editor said he "didn't need to talk" about the filming in detail to or go on a training course: it was "just terminology." This lack of template or job delineation for drone journalism could be problematic but also allows the process of navigating unchartered territory to be creative and organic.

\subsection{Meanings and Effects Sought by Operators}

Many pilots spoke enthusiastically about the creative and artistic possibilities of drone filming they enjoyed, the "buzz" or thrill of finding and producing aerial images and the aesthetic rewards of producing "pretty pictures," particularly the "breath-taking" or "wow" shots: One said that the images "blew my mind." Some were disparaging about the "pretty" shots and talked about striving for ever more unusual angles. The comments suggest that drone filming is still a ground-breaking and experimental activity and that a certain amount of thrillseeking is involved in filming.

The use of drone filming to produce dramatic effects was seen by most as a positive attribute, while others, particularly working in news, did not think it was appropriate, highlighting the contrasting requirements of the news and programme genres. However, when asked to pick a shot he had particularly enjoyed filming, one pilot working for a regional newsroom described a very dramatic tracking shot of a viaduct ending in a wide 'reveal' of the surrounding countryside.

Interviewees by and large recognised the narratives identified in previous research (Adams, 2018), although some criticised the research as "reading too much into it," but often needed to have the concepts explained, suggesting that their filming was done without consciously reflecting on its deeper significance or effect. The idea that bird's-eye views might give an audience a sense of imaginary omnipotence, as described by McCosker (2015, pp. 2, 5) was reinforced by the pilot who revealed that these are referred to in the newsroom as "God-shots." One editor indicated that drone footage was useful as a kind of marketing tool to "show off" the region; it was also regarded simply as an effective way of conveying "information." Most interviewees dismissed the idea that drone journalism would ever remind viewers of surveillance or the military but they could recognise it in other types of programmes.

A few operators and journalists articulated the opinion that the aerial shots can be used to allow the viewer to think or wonder, in their words, as a "breathing space, a thought." An extended version of the story online could "let them breathe," and by giving space to the footage, "allow [the viewer] to relax; people are so pressured." This resonates with the idea that drones can bring viewers some kind of Aufklärung (enlightenment; Jablonowski, 2014) and access to deep, even philosophical or existential thinking, by taking their view skyward (McCosker, 2015, p. 15). Some delved further into the question of why people liked to see aerial shots. One drone journalist cited a "sense of global connection": Viewers could feel they were "a small part in a massive world" or as Monaco (2000) puts it, "an abstract...global" point of view (p. 205).

\subsection{The Influence and Effect of Drone Operators on Journalism}

Most operators found challenging the idea that immersing the viewer might result in sacrificing objectivity on the altar of audience engagement. Several said it was indeed their aim: One said about the viewers, "I want them to be immersed," while another common view was that immersion was acceptable as long as there was context to go with it. In contrast at least one journalist baulked at the idea of immersion, insisting that, "we're telling stories rather than giving experiences." One editor felt that his audience desired an aerial view because "it takes our viewers to places they wouldn't normally go." He regarded the drone as a pioneering tool because it was "going somewhere new."

The operators' motive for getting into the field often came from a passion for technology and 'gadgets,' suggesting that their interest in innovation might drive new practices. Operators said "innovation will continue" in future as more "sophisticated shots" are looked for, and that "a different camera technique" would at some point supercede drone filming. "People are used to drone shots now, so you're looking for something different," explained one interviewee, in line with Cardoso's observation that an audience is quickly satiated (2015, p. 43). Perhaps the operators' presence itself helps to drive innovation more than ever, in an industry which tends to bow to the narrative agency of technology (Stewart, 2009, p. 45). The use of drones is also potentially a gender issue, in the context of the dearth of women professionals in the industry (Kuzma \& Dobson, 2019).

Beyond this, pilots and journalists (especially those working in programmes) felt pressured by market forces to attract viewers away from more popular commercial outlets by being "filmic, cinematic." "We're competing against Netflix," was one regional editor's view. One journalist suggested that the resources spent on drones were potentially being diverted away from quality journalism, because it was a cheaper way to provide eye-catching news: "Journalism needs more resources to investigate," she said. This recognises that UAVs are rarely necessary for newsgathering and cannot replace the skills of an investigative journalist (Jolley, 2014, p. 6; Marron, 2013). This reference to the political-economic context was rare 
in the interviews and may indicate a lack of interest in investigative journalism by pilots, who, after all, would be out of work if money was diverted back to hiring more reporters.

The interviewees all felt drones had been "good for journalism," (in its normative role as Fourth Estate), by providing a "unique perspective," illustrating "scope and scale" and offering new story-telling techniques. Some defended the use of dramatic shots as necessary "to engage people." They also provided examples of crucial story content (an illegal recycling dump, a flood breach) which had created programming. There was no acknowledgement that seeing scenes from above using drone techniques can potentially be counter-productive and create a "form of blindness" to the story (Lee-Morrison, 2015 , p. 214). There were mixed views about how much the UAV had actually changed journalism. One said it had "changed the game a bit" while another claimed only the style and quality of the material broadcast had changed. Another operator indicated that "it changes things" dramatically in terms of his role and status. One (ex-policeman) pilot expressed concern about intrusion into privacy or revealing "sensitive intel," demonstrating a consciousness of the law, of the drone user's power and responsibility and of how an individual's particular (non-journalistic) background can influence the output.

\section{Conclusion: In and Out of Control}

While the power of drone journalism may still not be fully understood (Radnor, 2014), especially in an era where the old newsroom job delineations are blurred, this research takes clear steps towards that comprehension. It highlights the crucial and under-valued role of the drone operator, portrays the complex and varied relationship between them and their journalistic counterparts and reveals their powerful influence on the evolution of journalism today.

The article reveals the importance of the initial stage of producing drone journalism: the operator's often private and unpredictable experience of discovering the pictures, when their creativity, skills and imagination are at play as they experiment with the technology and test out possibilities. When the journalist/editor sees the footage, they will approach it with their set of news and ethical values and journalistic skills. In the ensuing dialogue, choices and decisions are made which contribute to the final edit and the published product, influenced by technological development, market forces and corporate interests, such as the pressure of ratings and audience size and reach: Technology and commerce driving 'news as escapism.'

The interviews underscore earlier research which has shown that aerial images present new perspectives and 'players' to viewers and that they continue to be highly prized in video journalism. The more important the pictures, the more important the person who takes them, yet interviewees indicated that the changing role of the operator was barely discussed or accounted for in the workplace, even though drone filming had transformed their working lives.

Instead of having equal or 'dual' control, the journalist and operator (whose input may take place at different times), are better described as being "in and out of control." Their aims usually align but due to the new technology, responsibilities and highly skilled nature of drone filming, a knowledge gap has opened up between them.

This article clarifies that aerial shots can be positive for journalism, enriching it through alternative perspectives, stronger audience engagement and new opportunities to trigger their imagination, sense of wonder and 'blue skies thinking.' The operators' comments reveal the potential value of "the wow factor," "fairground" and "floating shots" and show that without their new creative freedom, the "mind-blowing" images in video journalism would not exist. Drones represent a clear trend away from quality journalism and towards producing marketable, 'pretty' pictures and immersive, escapist moments, often being used to 'prettify' and dramatize a story, prioritising engagement over objectivity. Pilots enjoy the experience of deliberately "flying" the viewer, letting them feel a loss of control yet at the same time the range of voices and difficult questions vital for quality reporting is reduced. Operators and journalists do not always appear to know why or how this is happening, where it is leading drone journalism and which 'new value networks' it may be signalling; thus the direction of travel is not being planned or thought out.

Stories are being experimented with and told in different ways from the past; the technical and commercial interests of a neo-liberal environment are challenging quality journalism as never before and the camera operator has unprecedented power. I contend that journalists themselves would benefit from learning more about the potential-good and bad-of drones in journalism and from realising how, when and why the output is being driven by their use. A closer working relationship and understanding between journalist and operator could help to close this knowledge gap, bring back 'dual control' and enhance the quality of drone journalism. There is a case for further examination of this topic and for continuing to ask how the increased use of aerial footage is impacting the audience, as TV and online media reach "peak drone."

\section{Future Directions}

It is still not clear why viewers love to see aerial footage. One reporter/operator suggested that wide aerial shots may give viewers the sense of awe at their place in the universe. It could be simply a desire to see more of the natural world. More research would be useful to tease this out through interviews with professionals and audiences. Drones may well be changing the way we see but certainly the 'wow factor' associated with aerial shots is still impressing audiences and does not look like going away. More training for both journalists and operators 
could be useful yet I could find few if any appropriate drone journalism courses outside universities beyond technical ones. Future research into new technological developments such as live broadcasting, streaming and new types of lenses and batteries will be required to keep pace with this field. Any researchers into drone filming should be conscious of the overwhelmingly male dominance of this sector of industry. Although women drone pilots are increasing, they make up just $5.8 \%$ of certified operators in the US (UAV Coach, 2019). Investigations are well overdue into the role played by gender, and other diversity factors, to determine further who is 'calling the shots' in the production of drone journalism.

\section{Conflict of Interests}

The author declares no conflict of interests.

\section{References}

Adams, C. (2018). Tinker, tailor, soldier, thief: An investigation into the role of drones in journalism. Digital Journalism, 7(5), 658-677.

Auslander, P. (1999). Liveness: Performance in a mediatized culture. London: Routledge.

Belair-Gagnon, V., Owen, T., \& Holton, A. E. (2017). Unmanned aerial vehicles and journalistic disruption: Perspectives of early professional adopters. Digital Journalism, 5(10), 1226-1239.

Blöbaum, B. (2016). Trust and communication in a digitized world. Cham: Springer International Publishing.

Cardoso, R. (2015). Flesh and the beholder: Towards a phenomenology of digital viewing. In T. Kristensen (Ed.), The cultural dimension of visuality: Visual organisations. Liverpool: University Press.

Chamayou, G. (2014). A theory of the drone. New York, NY: The New Press.

Choi-Fitzpatrick, A. (2014). Drones for good: Technological innovations, social movement, and the state. Journal of International Affairs, 68(1), 19-36.

Curran, J. P., \& Gurevitch, M. (2005). Mass media and society (4th ed.). London: Arnold.

Davies, N. (2008). Flat earth news. London: Chatto \& Windus.

de Beer, A. S., \& Merrill, J. C. (Eds.). (2008). Global journalism: Topical issues and media systems (5th ed.). Boston, MA: Pearson.

Deuze, M. (2005). What is journalism? Professional identity and ideology of journalists reconsidered. Journalism, 6(4), 442-464.

Deuze, M. (2008). Understanding journalism as newswork: How it changes, and how it remains the same. Westminster Papers in Communication and Culture, 5(2), 4-24.

Dominick, J. R., Wurtzel, A., \& Lometti, G. (1975). Television journalism vs. show business: A content analysis of eyewitness news. Journalism Quarterly, 52(2), 213-218.
Dorrian, M., \& Pousin, F. (Eds.). (2013). Seeing from above: The aerial view in visual culture. London and New York, NY: IB Tauris.

Dworkin, S. L. (2012). Sample size policy for qualitative studies using in-depth interviews. Archives of Sexual Behaviour. https://doi.org/10.1007/s10508-0120016-6

Golding, P., \& Elliott, P. R. C. (1979). Making the news. Harlow: Longman Publishing Group.

Greenwald, G. (2014). No place to hide: Edward Snowden, the NSA, and the US surveillance state. London: Hamish Hamilton.

Gynnild, A. (2014). The robot eye witness. Digital Journalism, 2(3), 334-343.

Gynnild, A., \& Uskali, T. (2018). Responsible drone journalism. London: Routledge.

Hamilton, T. (2015, February 2). Drone journalism is coming, like it or not. Corporate Knights. Retrieved from http://www.corporateknights.com/channels/ connected-planet/drone-journalism-14228768

Hesse-Biber, S. L., \& Leavy, P. L. (2005). The practice of qualitative research. Thousand Oaks, CA: SAGE Publications.

Hunt, D. M. (1999). OJ Simpson facts and fictions: News rituals in the construction of reality. Cambridge: Cambridge University Press.

IFJ. (2020). Global Charter of Ethics for Journalists. International Federation of Journalists. Retrieved from https://www.ifj.org/who/rules-and-policy/ global-charter-of-ethics-for-journalists.html

Jablonowski, M. (2014, September 29). Would you mind my drone taking a picture of us? Photomediations Machine. Retrieved from http://photomediations machine.net/2014/09/29/would-you-mind-mydrone-taking-a-picture-of-us

Jolley, R. (2014). Seeing the future of journalism and its power. Index on Censorship, 43(3), 3-6. https://doi. org/10.1177/0306422014550968

Krisis. (2017). Dronedeutung: Introduction. Journal for Contemporary Philosophy, 2017(1). Retrieved from http://krisis.eu/dronedeutung-introduction

Kuzma, J., \& Dobson, K. (2019). Gender diversity in the UAV (Drone) industry. International Journal of Gender, Science and Technology, 10(3), 366-377.

Lee-Morrison, L. (2015). Drone warfare: Visual primacy as a weapon. In T. Kristensen (Ed.), The cultural dimension of visuality: Visual organisations. Liverpool: University Press.

Lee-Wright, P., Phillips, A., \& Witschge, T. (2011). Changing journalism. London: Routledge.

Levine, B. (2014, May 23). Flocks of airborne camera drones will change journalism-and spying. Venturebeat. Retrieved from https://venturebeat.com/ 2014/05/23/flocks-of-airborne-camera-drones-willchange-journalism-spying

Marron, M. B. (2013). Drones in education. Journalism and Mass Communication Educator, 68(2), 95-98.

McCosker, A. (2015). Drone media: Unruly systems, rad- 
ical empiricism and camera consciousness. Culture Machine, 16(1), 1-21.

McQuail, D. (2013). Journalism and society. Los Angeles, CA: SAGE Publications.

Monaco, J. (2000). How to read a film. The world of movies, media, and multimedia: Language, history, theory. New York, NY: Oxford University Press.

NUJ. (2018). NUJ code of conduct. National Union of Journalists. Retrieved from https://www.nuj.org.uk/ about/nuj-code

Overholser, G. (2009, September 16). What is journalism's place in social media? NiemanReports. Retrieved from https://niemanreports.org/articles/ what-is-journalisms-place-in-social-media

Phillips, A. (2014). Journalism in context: Practice and theory for the digital age. London: Routledge.

Radnor, A. (2014, June 7). Drones: An eye in the sky. The Guardian. Retrieved from https://www. theguardian.com/artanddesign/2014/jun/07/droneseye-in-the-sky

Ray, V. (2003). The television news handbook: An insider's guide to being a great broadcast journalist. London: Macmillan.

Rocha, B. (2016, October 4). How drones are changing tourism marketing. LinkedIn. Retrieved from https:// www.linkedin.com/pulse/how-drones-changingtourism-marketing-read-marketers-brands-rocha

Rothstein, A. (2015). Drone. London: Bloomsbury.

Roug, L. (2014, May 1). Eye in the sky. Columbia Journalism Review. Retrieved from http://archives.cjr.org/ cover_story/eye_in_the_sky.php

Shapiro, I. (2014). Why democracies need a functional definition of journalism now more than ever. Journalism Studies, 15 (5), 555-565.
SPJ. (2014, September 6). Code of ethics. Society of Profession Journalists. Retrieved from http://www.spj. org/ethicscode.asp

Stewart, G. (2009). Digital fatigue: Imaging war in recent American film. Film Quarterly, 62(4), 45-55. Retrieved from http://fq.ucpress.edu/content/62/4/ 45.full.pdf+html

UAV Coach. (2019). 5.8\% of certified drone pilots are women. UAV Coach. Retrieved from https:// community.uavcoach.com/topic/5478-58-ofcertified-drone-pilots-are-women

Vanzura, M. (2019). View from above: An embodied notion of authority and power. Paper presented at Journalism from Above Workshop, Mid Sweden University, Sundsvall, 19-20 September 2019.

Waite, M. (2014). Journalism with flying robots. The ACM Magazine for Students, 20(3), 28-31.

Wallace, S. (2009). Watchdog or witness? The emerging forms and practices of videojournalism. Journalism, 10(5), 684-701.

Waterson, J. (2014, February 25). This amazing footage shows why drone journalism is about to go mainstream. Buzzfeed. Retrieved from https://www. buzzfeed.com/jimwaterson/this-amazing-footageshows-why-drone-journalism-is-about-to?utm_term $=. \mathrm{tt} 78 \mathrm{~m} 8 \mathrm{vM} 6 \mathrm{q} \# . \mathrm{yr} I X 7 \mathrm{Xz9PZ}$

Wyndham, S. (2017, April 14). Preventing drone fatigue: How to get better shots. Red Shark News. Retrieved from https://www.redsharknews.com/production/ item/4498-preventing-drone-fatigue-how-to-getbetter-shot

Zuckerman, E. (2013). Rewire: Digital cosmopolitans in the age of connection. New York, NY: W.W.Norton.

\section{About the Author}

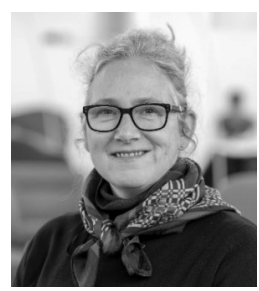

Catherine Adams has been a Journalist for local, national and international print, online, agency, radio and TV outlets for over thirty years, including periods as a newsreader and a foreign correspondent for the BBC World Service. As a Senior Lecturer at Nottingham Trent University she has written journal articles on journalism for Gender and Society, Digital Journalism and Journalism Practice. She is a local branch official for the National Union of Journalists. 